\title{
Radial nerve palsy following closed unreamed nailing of the humeral diaphysis: A case report
}

\author{
Sinopidis Chris ${ }^{1}$, Bougiouklis Dimitrios ${ }^{2 *}$ and Gliatis John ${ }^{3}$ \\ ${ }^{1}$ Orthopaedic Director, Specialist in Shoulder and Elbow Surgery, Medical Interbalkanian Center of Thessaloniki, Greece \\ ${ }^{2}$ Locum Consultant of Orthopaedic Department, General Hospital of Pyrgos, Greece \\ ${ }^{3}$ Associate Professor of Orthopaedics and Head of Sports Medicine Unit, University Orthopaedic Department, University General Hospital of Patras, Greece
}

\begin{abstract}
Background: Intramedullary nail gains increasing popularity as an option to treat fractures of the humeral shaft. The proximity of the radial nerve to the fracture site is always a concern for iatrogenic nerve damage during nailing. However, there is no documented report of direct radial nerve palsy due to nailing process.

Case report: A forty-two years old man was involved in a road traffic accident and he sustained a close fracture of his left humeral diaphysis and a close fracture of the diaphysis of his ipsilateral tibia. Pre-operative examination did not reveal any neurovascular deficit. Due to the high energy of the injury, the patient was conduced to the operating Room where both fractures were stabilized with unreamed nailing. In the immediate post-operative period, he developed complete radial nerve palsy and it was urgently decided the remove of the nail. The radial nerve was found to be bruised but maintained its continuity. The humeral fracture was stabilized with plate fixation. Six months later, the radial nerve was, partially, recovered. A full motor and sensory recovery of the nerve was observed ten months later.
\end{abstract}

Conclusion: Even if it's rare, there is a risk of damage of radial nerve during unreamed nailing of a fracture of the midshaft of the humerus. In these cases, the use of somatosensory; during the implantation of the nail, evoked potential monitoring, could offer us the opportunity to find the entrapment of radial nerve.

\section{Background}

Functional bracing as the standard conservative treatment for most humeral shaft fractures has been successful with predictably high union rates $[1,2]$. However, it is losing popularity, due to the need of prolonged immobilization, to achieve solid union followed by vigorous rehabilitation to restore joint function and muscle strength. Operative treatment for these fractures is considered in specific situations including patients with spinal cord (high quadriplegia), brachial plexus or multiple injuries, in open fractures or those associated with neurovascular injuries, in the floating elbow, and in cases where a satisfactory reduction cannot be maintained by closed methods [3-5]. The two commonest surgical options are open reduction and internal fixation with a plate or closed reduction and intramedullary nailing. Plate fixation offers the advantage of anatomical fracture reduction but is associated with a high non-union rate, high infection rate and potential injury to the radial nerve, especially if later removal is required [6]. Closed intramedullary nailing has certain advantages like being closer to the normal mechanical axis of the bone and acting as a load sharing device. Bending forces and consequent fatigue failure are less. Since the fracture is not exposed directly and soft tissue dissection is much less, the fixation is more biological and with less stress shielding and chances of iatrogenic nerve injury are also reduced [7]. However, the procedure has its complications. The most common of these are the failed reduction, the morbidity associated with the insertion site through the rotator cuff [8] and the iatrogenic fracture comminution during reaming. Potential injury to neurovascular structures include the risk to the radial nerve from canal preparation and nail insertion, to the axillary nerve from the proximal locking and to the radial, musculocutaneous and median nerves and to the brachial artery from the distal locking. Several studies reported partial radial nerve injuries after closed IM nailing of the humerus that recovered with no additional intervention. According with the study of McCormack at al. [9], the rate of the radial nerve palsy after interlocking IM nailing varies from $3-14 \%$. However, there are no reported cases to our knowledge, with radial nerve entrapment within the fracture site after intramedullary nailing of the humerus. We present a patient with fracture of the humeral diaphysis who developed post-operative radial nerve palsy due to entrapment at the fracture site around the nail.

\section{Case report}

A forty-two-year-old man was involved in a road traffic accident 2 years ago following excess alcohol intake. He sustained a close multifragmented AO type-B2.2 fracture of his left humeral diaphysis (Figure 1) and a close AO type-B2 fracture of the diaphysis of his ipsilateral tibia. Pre-operative examination did not reveal any neurovascular deficit in the upper or lower limbs. The indication for operative treatment was the high energy nature of the injury and that he had fractured another long bone. He underwent closed unreamed nailing of the humerus with a Polarus nail (Acumed, USA) (Figure 2). The tibial fracture was also stabilized with an unreamed nail. In the immediate post-operative period he developed complete radial nerve palsy as he was unable to actively extend his wrist and fingers and had complete absence of sensation over the dorsum of his left hand in the

${ }^{\star}$ Correspondence to: Bougiouklis Dimitrios, Orthopaedic Department of G.H. of Pyrgos, Greece, Tel: 003-2621-361-198, E-mail: dimmed@hotmail.com

Key words: radial nerve, humerus, diaphysis, nail

Received: July 06, 2018; Accepted: July 25, 2018; Published: July 30, 2018 


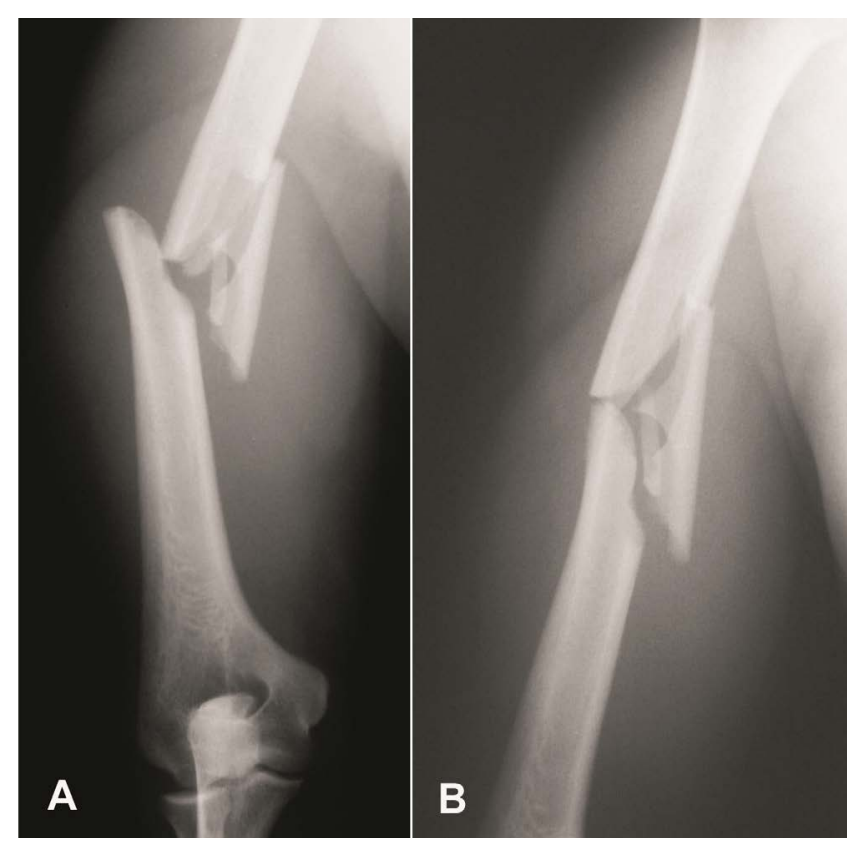

Figure 1. AP and oblique radiographs of this AO type-B2.2 fracture of the middle third of the humeral diaphysis, showing the large medial butterfly along with varus angulation of the distal fragment

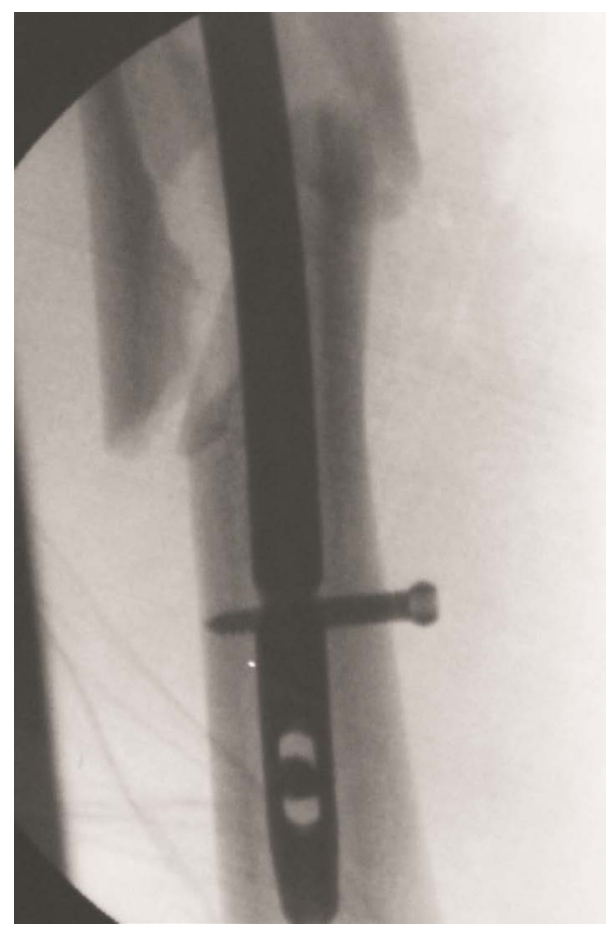

Figure 2. Fluoroscopic view taken in the operating theatre to show the fracture site and the position of the unreamed nail in the humeral diaphysis

territory supplied by the radial nerve. He was transferred urgently to the operating room (within 12 hours from the primary procedure) for radial nerve exploration. The lateral approach to the humerus was utilized and the radial nerve was found entrapped around the nail between the two main bony fragments (Figure 3). The nerve, when removed of the nail, was released. It was found to be severely bruised but was still in continuity. The fixation was converted to plate stabilization with two lag screws and an 8-hole large DCP neutralization plate. Artificial bone graft was added to optimize the healing process. At the 3-month postoperative follow-up the fracture was healed (Figure 4) and the patient had some sensory recovery but no sign of motor recovery in his left hand. Nerve conduction studies showed severe nerve damage but also showed partial re-innervation to the triceps muscle. At six months, there was partial recovery of the radial nerve with grade $4 / 5$ power in all the extensor muscle groups. Sensation had returned to normal apart from occasional mild discomfort due to pins and needles. At ten months there was full motor and sensory recovery.

\section{Discussion}

Despite the close proximity of the radial nerve to the humeral shaft, the rate of radial nerve palsy after closed intramedullary nailing of the humerus, is not as high as it would be expected. Several series in the literature report only a few nerve palsies after nail insertion. Rommens

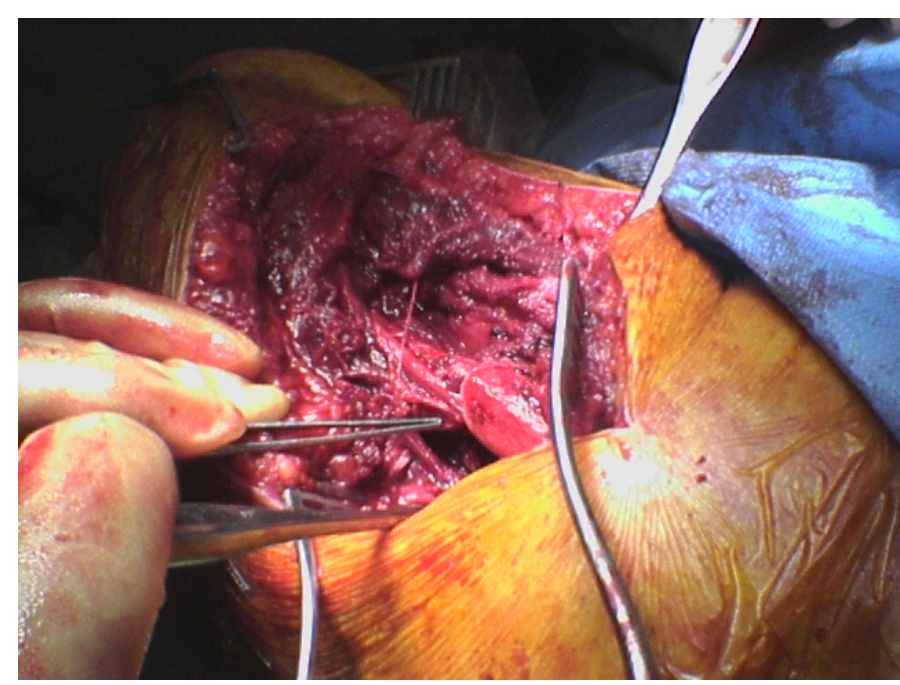

Figure 3. Photograph taken in the operating theatre at the time of exploration. The radia nerve has been identified entrapped between the two main fracture fragments and the nail

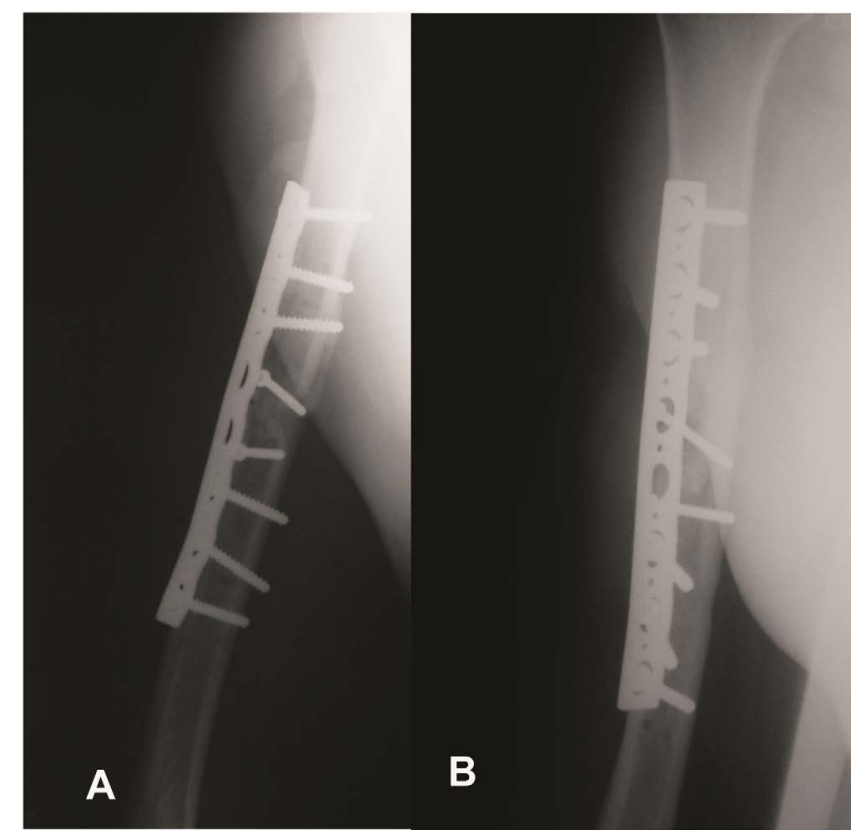

Figure 4. AP and lateral radiographs taken three months following the fixation with a large DCP plate showing complete fracture union 
et al. [7] reported only one case in a series of 39 patients that recovered in three months without nerve exploration. Crates et al. [10] reported two iatrogenic post-operative nerve palsies after insertion of a humeral nail. In one patient, the nail was inserted after reaming of the shaft, while in the other was unreamed. In both cases the nerve was explored immediately after the operation and was found to be in continuity, but it was not entrapped between the fragments. In the series of Lin et al. [11] where the authors presented 161 patients who underwent humeral nailing, post-operative radial nerve palsy occurred in three patients, two after acute fractures treated by closed nailing and another one non-union treated by open nailing and bone grafting. All of them had normal recovery within 2 months. It was not stated whether the nerve was explored. They supported the experience of Crates and Whittle that radial nerve palsy was mostly caused by manipulation of the fracture and that functional recovery was mostly to be expected. Ingman and Waters reported one case in 41 patients after humeral nailing, however this nerve palsy was present before the operation and it recovered 6 months post-operatively. Other series do no not report any nerve injuries [12].

External rotation spiral fractures of the humerus represent a specific category, where the radial nerve may be entrapped among the fracture fragments. First described by Holstein and Lewis [13], it is a fracture of the distal third of the humeral shaft which has a spiral configuration with the distal fragment having proximally migrated and radially angulated. Lin reported cases with radial nerve entrapment, even in fractures of the midshaft of the humerus, which also had a spiral configuration, with external rotation force being the most common mechanism of injury. In such cases, an undispaced posterior triangular fragment was responsible of radial nerve entrapment. [14]. He noted that radial nerve entrapment may occur more frequently after highenergy trauma, especially if there is varus angulation. In these cases, it is mandatory to explore the radial nerve before fracture reduction, regardless of the presence or absence of nerve palsy.

The fracture presented in this report does not belong to the category described by Holstein and Lewis, as it was located in the humeral midshaft and not in the distal third. It is resulted from high-energy trauma, but there were no signs of external rotation force. There was also comminution with a medial butterfly fragment, which according to the study by Lin, could not cause nerve's entrapment. Reaming of the bone would have caused irreversible damage to the nerve. It is not clear, from the previous reports, if postoperative nerve palsy is an indication for immediate exploration. Several studies in which has been performed a late exploration of a radial nerve palsy, have shown that it has been a laceration or entrapment of the nerve in $6-25 \%$ of the cases $[15,16]$. Moreover, the systematic review performed by Shao and colleagues [17] showed a spontaneous recovery rate of $70 \%$, but an overall recovery rate of only $88 \%$. Subsequently, there are some cases of radial nerve palsy with closed humerus fractures in which a delayed nerve exploration can compromise ultimate recovery. In our case, nerve recovery would not have occurred as it would be entrapped in the callus formed later at the fracture site. Therefore, a prolonged period of observation, would have led in nerve's atrophy and motor endplate loss and a significant period of time in which the patient would be lack of hand function.

At this point, it is extremely important to emphasize that in our case, the use of somatosensory evoked potential monitoring during the implantation of the nail, will have offered us the opportunity to find the entrapment of radial nerve. Actually, Mills et al. [18] used the somatosensory evoked potential monitoring in a succession of 13 patients with humeral shaft fracture treated with nailing [18]. In this way, in a patient they managed immediately to find the nerve entrapment and realize open exploration. In two other patients, significant changes of the somatosensory evoked potential were noticed, either during the manipulation of the nail, or during the distal interlocking. Lastly, it is important to highlight the fact that the ability of a highly accurate ultrasound scanning could help us in checking the continuity of the nerve [19].

\section{Conclusion}

In those humeral fractures with radial nerve entrapment, it is difficult to decide whether an early exploration it is necessary. In some types of humeral shaft fractures, as in our case, the use of somatosensory evoked potential monitoring during the implantation of the nail, could offer us the opportunity to find the entrapment of radial nerve. Also, a highly accurate ultrasound scanning might be a useful tool in checking continuity of the nerve. To our knowledge, this is the first reported case in the English literature of radial nerve entrapment after closed humeral nailing. Although it is an isolated case, it indicates the risk of nerve damage after nailing of fractures of the humerus midshaft that are not the result of an external rotation force. Post-nailing radial nerve palsy may not always be the result of traction during manipulation and therefore we believe this to be an indication for immediate nerve exploration.

\section{References}

1. Sarmiento A, Kinman PB, Galvin EG, Schmitt RH, Phillips JG (1977) Functional bracing of fractures of the shaft of the humerus. J Bone Joint Surg Am 59: 596-601. [Crossref]

2. Ikeda K, Osamura N (2014) The radial nerve palsy caused by embedding in the humeral shaft fracture - a case report. Hand Surg 19: 91-93. [Crossref]

3. Bell MJ, Beauchamp CG, Kellam JK, McMurtry RY (1985) The results of plating humeral shaft fractures in patients with multiple injuries. The Sunnybrook experience. $J$ Bone Joint Surg Br 67: 293-296. [Crossref]

4. Brumback RJ, Bosse MJ, Poka A, Burgess AR (1986) Intramedullary stabilization of humeral shaft fractures in patients with multiple trauma. J Bone Joint Surg Am 68: 960-970. [Crossref]

5. Hems TE, Bhullar TP (1996) Interlocking nailing of humeral shaft fractures: the Oxford experience 1991 to 1994. Injury 27: 485-489. [Crossref]

6. Foulk DA, Szabo RM (1995) D iaphyseal humerus fractures: natural history and occurrence of nonunion. Orthopedics 18: 333-335. [Crossref]

7. Rommens PM, Verbruggen J, Broos PL (1995) Retrograde locked nailing of humeral shaft fractures. A review of 39 patients. J Bone Joint Surg Br 77: 84-89. [Crossref]

8. Robinson CM, Bell KM, Court-Brown CM, McQueen MM (1992) Locked nailing of humeral shaft fractures. Experience in Edinburgh over a two-year period. $J$ Bone Joint Surg $\operatorname{Br}$ 74: 558-562. [Crossref]

9. McCormack RG, Brien D, Buckley RE, McKee MD, Powell J, et al. (2000) Fixation of fractures of the shaft of the humerus by dynamic compression plate or intramedullary nail. A prospective randomised trial. J Bone Joint Surg Br 82: 336-9. [Crossref]

10. Crates J, Whittle AP (1998) Antegrade interlocking nailing of acute humeral shaft fractures. Clin Orthop Relat Res: 40-50. [Crossref]

11. Lin J, Shen PW, Hou SM (2003) Complications of locked nailing in humeral shaft fractures. J Trauma 54: 943-949. [Crossref]

12. Elzohairy MM (2012) Management of Radial Nerve Palsy Associated with Humeral Shaft Fractures by Closed Interlocking Intrameduallary Nail. J Trauma Treatment 1: 121.

13. HOLSTEIN A, LEWIS GM (1963) FRACTURES OF THE HUMERUS WITH RADIAL-NERVE PARALYSIS. J Bone Joint Surg Am 45: 1382-1388. [Crossref]

14. Blum J, Machemer H, Rommens PM (2002) Risk of radial nerve injury during distal interloking of short humeral nail. Osteo Trauma Care 10: 73-75.

15. Ekholm R, Adami J, Tidermark J, Hansson K, Törnkvist H, et al. (2006) Fractures of the shaft of the humerus. An epidemiological study of 401 fractures. J Bone Joint Surg $\operatorname{Br}$ 88: 1469-1473. [Crossref] 
16. Hugon S, Daubresse F, Depierreux L (2008) Radial nerve entrapment in a humeral fracture callus. Acta Orthop Belg 74: 118-121. [Crossref]

17. Shao YC, Harwood P, Grotz MR, Limb D, Giannoudis PV (2005) Radial nerve palsy associated with fractures of the shaft of the humerus: a systematic review. $J$ Bone Joint Surg Br 87: 1647-1652. [Crossref]
18. Mills WJ, Chapman JR, Robinson LR, Slimp JC (2000) Somatosensory evoked potential monitoring during closed humeral nailing: a preliminary report. $J$ Orthop Trauma 14: 167-170. [Crossref]

19. Ikeda K, Osamura N (2014) The radial nerve palsy caused by embedding in the humeral shaft fracture - a case report. Hand Surg 19: 91-93. [Crossref]

Copyright: $\mathbb{C} 2018$ Chris S. This is an open-access article distributed under the terms of the Creative Commons Attribution License, which permits unrestricted use, distribution, and reproduction in any medium, provided the original author and source are credited. 